\title{
Big data applications in accounting: Insights for higher education curriculum planning
}

\author{
Aimee Hoodlebrink, Ball State University, arhoodlebrin@bsu.edu \\ Allen D. Truell, Ball State University, atruell@bsu.edu \\ Jensen J. Zhao, Ball State University, jzhao@bsu.edu \\ Christopher B. Davison, Ball State University, cbdavison@bsu.edu \\ Edward J. Lazaros, Ball State University, ejlazaros@bsu.edu
}

\begin{abstract}
The purpose of this literature review is multifold. First, the speed of adopting big data tools by accountants will be discussed. Second, a review of some big data applications for accountants, their implications, and challenges for practice will be presented. Lastly, a discussion of implications for curriculum planning for those involved in accounting education programs will be put forth.
\end{abstract}

Keywords: Accounting, Big Data Applications, Curriculum Planning

\section{Introduction}

For a whole host of reasons, the accounting profession tends to be slow to change. For example, Schmidt, Church, and Riley (2020) noted several reasons why the profession is slow to implement emerging data analytics technology. The slow implementation is due to a combination of transitional issues, uncertainty, and costs. Accounting firms have used spreadsheet applications to analyze data and have extensive knowledge of its capabilities. Training staff on another system could bring many issues. Accounting firms are also risk-averse, and since they know that spreadsheet applications can perform the data analysis they currently need, they are not jumping at the opportunity to change. Finally, accounting firms have already spent time and money training their staff on the current data analysis software. The time and money that went into this training would become sunk costs if they were to change.

Although Schmidt, Church, and Riley (2020) noted these points to show how accounting firms rely on spreadsheet applications, they also pointed out some other accounting profession characteristics that prevent changes from occurring. First, the structure of an accounting firm is hierarchical. A hierarchy structure discourages any movement from the status quo, discouraging data analytics software changes. Accounting firms also face strong time constraints, especially in the spring. Time constraints further limit the ability to effectively train staff on new software and trust the staff to complete their tasks effectively and efficiently. Audits, in particular, also face a pricing issue. Even if additional data analysis brought a higher quality audit, there is little room and incentive to increase prices to perform the audit (Appelbaum, Kogan, \& Vasarhelyi, 2017). Additionally, Rezaee, Dorestani, and Aliabadi (2018) explained that the accounting standards hamper firms from adopting new technology quickly. Due to the accounting profession's 
inability to make quick technological changes, non-accounting professionals with enhanced data analytic capabilities have the opportunity to fill traditional accounting positions (Schmidt, Church, \& Riley, 2020).

Richins, Stapleton, Stratopoulos, and Wong (2017) explained that non-accounting professionals, namely in the technology sector, are already being hired over accountants for their data analytic skills. This practice increases competition and poses a threat to the accounting profession. The authors noted that the Big 4 accounting firms have begun implementing big data and more robust data analysis technologies, making the outlook and opportunity for accounting firms more promising. However, extensive data analysis can also lead to the automation of accounting-related tasks, like bookkeeping, staff auditor tasks, and report generation (Borthick \& Pennington, 2017; Richins, Stapleton, Stratopoulos, \& Wong, 2017). Nonetheless, Cockcroft and Russell (2018) noted that the accounting profession is best suited to manage and analyze big data. Accountants are already trusted with large amounts of client data and have the unique ability to add clarity to numbers.

The belief that accountants are well suited to manage big data creates opportunities in the accounting profession. Borthick and Pennington (2017) explained how analytic tools can help accountants solve persisting accounting and business problems. For example, patterns can better be identified, complete population testing is made possible, and better internal controls can be encouraged through the use of data analysis. Richins, Stapleton, Stratopoulos, and Wong (2017) further described that outliers can undergo more analysis and the tasks that require professional judgment cannot be easily automated, protecting accountants from technological advancements. However, Richins, Stapleton, Stratopoulos, and Wong (2017) also explained that additional changes need to be made in the profession and the training of staff in order for accountants to take full advantage of the opportunities presented.

\section{Big Data Accounting Applications}

This section of the literature review is divided into two sections. The first section reviews big data applications associated with management accounting. The second section explores big data applications connected to auditing. Let us begin with a review of big data management accounting applications.

\section{Management Accounting}

One area of accounting where big data is beginning to be used regularly is management accounting. Big data allows the analysis of both structured and unstructured data. Accountants regularly work with structured data, but they have the increased ability to work with unstructured data through big data analysis. Murthy and Geerts (2017) noted various sources from which big unstructured data can be retrieved and utilized by management accountants. For example, with increased Internet usage and online shopping worldwide, website logs are a perfect place to retrieve valuable data. Management accountants can mine information from these logs to better understand customer shopping habits and online advertising effectiveness. If management accountants can analyze this data, they can aid in the decision-making process relating to these items.

Another source of big data is social media. Murthy and Geerts (2017) explained that social media data consist of two types: commentary data and action data. Commentary data include the posts, comments, and mentions of a brand name or a product. Action data include the likes, comments, and reposts of the 
commentary data. Both types are essential to analyze to understand the reach and implications of the social media data. One challenge with social media data is that it can be difficult to associate this data to traditional financial data. Identifying the links between unstructured social media data and financial data is a task management accountants may be equipped with due to their experience with the industry and extensive knowledge of financial data. Location or existence logs are another source of big data for management accountants. This data can link objects to valuable information about inventory flow and other operational information that help management accountants make cost decisions and aid strategic planning. Communication repositories provide an additional source for unstructured data. These repositories are filled with text data that can be useful in decision making; however, extracting and cleaning this data can be difficult. Using all of the data sources Murthy and Geerts (2017) described, management accountants, can be more effective in their costing decisions and more useful in the decision-making process.

Cockcroft and Russell (2018) proposed that big data is arguably the most important asset on a company's balance sheet. Extensive data analysis can help companies gain competitive advantages through enhanced decision-making, stronger customer insights, and better fraud protection and prevention (Cockcroft \& Russell, 2018). Management accountants can utilize big data to help companies improve their financial performance and profitability (Dewu \& Barghathi, 2019). They also can use big data to improve reporting and decision-making functions. For example, by identifying anomalies through big data, a management accountant can better investigate those anomalies and improve reporting processes (Cockcroft \& Russell, 2018). Big data also allows management accountants to better compare and link financial and non-financial data, allowing more relevant information to support decision-makers (Cockcroft \& Russell, 2018). Big data enables management accountants to better forecast their cost and risk assessments, further helping the strategic planning process (Dewu \& Barghathi, 2019).

Beaulieu (2020) discussed how management accountants could utilize contract-based cost analytics to improve product costing decision-making. Product costing generally includes arbitrary decisions about allocating overhead. By using a contract-based cost analytic system, costs can be obtained directly from contracts and not pooled together. Big data can then use real-time information to produce live cost models based on internal and external sources. These models are based solely on the contract terms and have the potential to eliminate the overhead cost pool entirely, which is the main benefit of contract-based cost analysis. By eliminating overhead allocation, product costing information is timelier and easier to understand. Contract-based cost analysis also reduces estimation assumptions allowing for more accurate product costing data.

Additionally, negotiations involving sales and the cost of sales can be improved through contract-based cost analysis. The system merges the planning and negotiation functions, which alerts management of upcoming contract expiration dates. Finally, it allows management accountants to aid decision-makers in comparing the cost flows in different scenarios, which is necessary when making capital budgeting decisions. In many cases, capital budgeting decisions are based on accruals rather than real-time cash flows. Contract-based cost analysis allows these decisions to be based on cash flows, allowing for more accurate forecasting and better decision-making. The one drawback of contract-based cost analysis is that management accountants may not be as familiar with linear cost behavior assumptions. 


\section{Auditing}

Auditing is another area of accounting to which big data has been applied. Dewu and Barghathi (2019) explained some of these areas of application. Big data can be used to better identify fraud activities. Because more information is available to inspect with big data, the ability to improve fraud risk assessments and procedures is heightened. By analyzing the massive amount of information, detecting risky activities or suspicious transactions becomes easier. Qasim and Kharbat (2020) illustrated using social media data to look for potential litigation risk, business risk, internal control risk, and risk of management fraud. Identification of fraud has long been an area with which external auditors have struggled. With the help of big data, these assessments can improve.

Big data can complement the traditional audit evidence gathered from substantive tests and the enhanced ability to perform risk assessments. For example, big data and data analysis can help detect errors, misstatements, and violations of laws alongside traditional evidence (Dewu \& Barghathi, 2019). One issue with using big data to complement traditional audit evidence is introducing big data to auditors. Rose, Rose, Sanderson, and Thibodeau (2017) addressed this issue and found that big data should be introduced to auditors after gathering traditional audit evidence. The authors found that when big data was introduced to auditors before they performed audit procedures, auditors experienced difficulty recognizing patterns. Due to this difficulty, the value created from big data decreased substantially. The auditors experienced information overload in these cases and began to recognize meaningless patterns that threatened the effectiveness of the audit. However, if the big data visualizations were introduced after traditional audit evidence had been gathered, auditors could better recognize the patterns created from the big data and relate these patterns to management's assertions. This linkage prompted the auditors to become more concerned about potential misstatements and budget more hours for the audit, which increased the effectiveness of the audit, but potentially decreased the efficiency. Currently, no standards are specifying when big data visualizations should be introduced during an audit, so Rose, Rose, Sanderson, and Thibodeau's (2017) paper was able to identify the best timing for the introduction.

Audit standards, in general, lack guidance on the use of big data in practice. For example, Appelbaum, Kogan, and Vasarhelyi (2017) noted that clients increasingly rely on big data to conduct business, making audit trails harder to follow and fraud assessments more difficult. However, the audit profession is slow to utilize big data in its audit procedures. The slow implementation of big data into the profession may be due to the lack of direction from the standards (Appelbaum, Kogan, \& Vasarhelyi, 2017). If the standards were to provide more direction and encouragement for implementing big data into audit procedures, more audit firms would utilize it in their risk assessment and other audit phases. Standard setters would also need to consider adapting the quality of evidence requirements because more data does not equate to more effective data. However, the stringent current state of the audit standards makes data analytics difficult and even impractical in some situations. The standards allow the testing of $100 \%$ of a population, but they do not necessarily encourage it. For example, the authors noted that the sampling standards have not adapted to the increases in technology that make full population testing possible. If full populations were tested, auditors could spend less time identifying sampling risk and more time analyzing the high-risk transactions identified in the population.

Big data allows whole populations to be tested, which makes the continuous audit system possible as well. Cong, Du, and Vasarhelyi (2018) discussed how current financial reports are becoming less relevant in the 


\section{Issues in Information Systems}

information age. Current financial reports are not as timely as the other information users of the financial statements can retrieve. The current measurements for inventory, cash flows, and receivables are insufficient and based on accounting assumptions. Utilizing big data and a continuous audit system, realtime measurement, assurance, and reporting can be made possible. Continuous auditing can improve the comparability and articulation of financial reports to make them more relevant to the users. Cong, Du, and Vasarhelyi (2018) explained that a continuous audit system would also need to verify the financial data and the non-financial data of a company, which would make an audit more complex. Just as Appelbaum, Kogan, and Vasarhelyi (2017) described, Cong, Du, and Vasarhelyi (2018) discussed how the audit standards sparked issues regarding implementing a continuous audit system. Although a continuous audit system provides the benefits of real-time detection and correction of errors, the standards are bound to traditional audit procedures that involve sampling, materiality, and the use of estimates for valuing inventory and other items. Without the standards backing a continuous audit system, practicing auditors may not adapt and utilize big data to its fullest.

Rezaee, Dorestani, and Aliabadi (2018) discussed another way auditors can use big data in practice: time series analysis. Time series analysis allows auditors to identify financial and non-financial information patterns that can help them better understand the markets, industry, social media standing, challenges, and opportunities the client is facing. The enhanced understanding permits the auditor to make a better risk assessment and improve how the audit is planned, performed, and reported. Although the primary use of time series analysis is to forecast, the patterns derived from the analyses can be used to detect, prevent, and predict fraud. Although it is clear that time-series analyses are useful in conducting an audit, the authors explained that this type of analysis is only in the early stages of implementation into the profession.

Although time series analysis is only in the early stages of implementation, many audit firms are currently using software to analyze data within large datasets. For example, Smidt, Ahmi, Steenkamp, van der Nest, and Lubbe (2019) used a questionnaire to identify the extent to which significant data software is currently being used in the internal audit function. They found that most internal auditors still rely on traditional spreadsheet software despite the inability to handle large datasets, requirements for programming knowledge, and susceptibility to error. However, some auditors indicated that they used software that was better at handling big data. Examples of these software included ACL, IDEA, and Tableau. These types of software are commonly used to test controls and can handle larger datasets to identify patterns. Thus, even though some auditors are utilizing big data software, the implementation of big data usage into the audit profession can be significantly improved.

\section{Curriculum Planning}

This section of the literature review is divided into three sections. The first section reviews integrating information technology into the curriculum. The second section explores integrating big data into the curriculum. The third section examines the challenges associated with integrating big data into the curriculum. Let us begin with a review of integrating information technology into the curriculum.

\section{Integrating Information Technology into the Curriculum}

The need for increased data analytics skills has been recognized in the industry and in accounting education standards. For example, as Tapis and Priya (2020) noted, The Association to Advance Collegiate Schools of Business (AACSB) released Standard A5 in 2018 that included the importance of integrating information 
technology into accounting education. Tapis and Priya (2020) explained that this standard primarily focuses on two components: agility and adaptability. The authors explained that agility relates to being aware of technology in a variety of circumstances and understanding how technology can be used to aid in decisionmaking. Adaptability involves learning the basics of a type of technology, like in the classroom, and transferring those skills to other similar technologies, like the software student will use during their careers.

Along with the AACSB, practitioners, and professors have also pushed to integrate technology and big data into the accounting curriculum. Dewu and Barghathi (2019) interviewed accounting faculty and professionals to understand this need better. The professors interviewed did not believe students with the current curriculum would be ready to utilize big data in their future careers. Accounting education is based primarily on teaching the profession's concepts rather than using the technology accounting firms may utilize. The professors also explained that they thought it was essential to integrate more data analysis into the curriculum. The practitioners agreed with the professors. Many practitioners noted that extensive training has to be given to college graduates, and performance is always slow to improve. The practitioners explained that if more technology was introduced in college, performance might be able to improve quicker. In particular, they described the importance of teaching students how to work with big data by using software from the profession, like Tableau.

\section{Integrating Big Data into the Curriculum}

Dzuranin, Jones, and Olvera (2018) also surveyed accounting faculty. Faculty saw the importance of integration and believed a stand-alone course and integration of data analytics into current accounting courses would be the most beneficial way to improve students' skills. Using this survey, the authors proposed three methods to integrating big data into the accounting curriculum: the focused approach, the integrated approach, and the hybrid approach. The focused approach involves a stand-alone data analytics course that teaches students about data creation, data mining, data storage and use, and data security. The limitation of this approach is the little room left in accounting student's class schedules. Adding a threecredit-hour class to the accounting core may be infeasible. The integrated approach weaves data analytics into existing accounting courses. This approach would better combine analytical and accounting knowledge by utilizing software tools such as ACL, IDEA, and Tableau. The limitation of this approach is that accounting courses are already packed full of the necessary information that is particularly relevant to the CPA exam. Therefore, including data analytics in an entire course may be difficult. The final approach, hybrid, combines the focused and integrated approach. Colleges or programs could include a stand-alone data analytics course and encourage integrating analysis concepts into existing accounting courses.

Zhan, Her, Hu, and Du (2018) expanded on Dzuranin, Jones, and Olvera's (2018) ideology by developing deeper strategies for the focused and integrated approaches. The authors specifically noted the need to teach skills beyond spreadsheets, like obtaining and cleaning data and understanding how to use different analytical tools and techniques. Students must also be taught how to apply their data analytic skills to decision-making and communicate decisions based on data analysis. The authors believed the focused approach must emphasize data preparation, modeling, and evaluation as it applies to various business challenges and opportunities. The three goals of a stand-alone accounting data analytics course would be to develop students' analytical mindsets and critical thinking skills, identify value creation opportunities through data analysis, and analyze and estimate value through data analysis. 
For the integrated approach, Zhan, Her, $\mathrm{Hu}$, and $\mathrm{Du}$ (2018) examined introductory, intermediate, and management accounting course integration. Introductory courses could include a financial statement analysis project that prompts students to collect, extract, and transform data through the four financial statements. This project can help students understand and utilize descriptive analytics. In the intermediate course integration, the authors ensured they consider the already entire course. They suggest a four-class module around the time the concept of earnings management is introduced. The first class would discuss the ways managers can manipulate earnings, and the second class would introduce discretionary accrual models to show students how revenues and expenses can be manipulated. The third class would involve a step-by-step demonstration of using spreadsheet applications for fundamental statistical and regression analysis. Finally, the fourth class would introduce a case project where students must retrieve data from the SEC's EDGAR database, transfer the data to a spreadsheet application, clean the data, run regressions, write a report, or present their findings. The final course that was examined was management accounting. The authors believed the best way to integrate data analysis into this course is through cost behavior and estimation. Cost behavior and estimation can be analyzed by using big data and activity-based costing methods. Introducing data analysis at this point in the management accounting course would allow students to understand how a management accountant can use big data.

Qasim and Kharbat (2020) also suggested ways of integrating data analytics into existing accounting courses. They believe the necessary skills students need to learn are statistical techniques, data mining, data management, modeling, analysis, learning systems, and visualization techniques. The introductory courses were suggested to include an overview of the concepts related to data analysis by using cases, lectures, and readings. These courses should explain how data analytics can be applied to business scenarios. The intermediate course should utilize cases, lectures, debates, and presentations to convey how analytic techniques can be used for financial statements and decision-making. The authors included a suggestion for integrating data analytics into the senior-level auditing course. These classes can describe and use case studies to explained the analytical techniques used when conducting an audit and link audit analytics to continuous monitoring and process improvement. The authors emphasized that case studies were most likely the best tool to teach data analytics to students.

Another study analyzed the integrated approach as well. Similar to the previous studies, Sledgianowski, Gomaa, and Tan (2017) suggested using EDGAR in financial accounting courses, introducing XBRL concepts, and utilizing software in the marketplace, like Quick Books, Microsoft Dynamics GP, Quicken, and SAP ERP. For management accounting courses, the authors believed producing visualizations through spreadsheet software and Tableau would teach students how to use data analytics to make decisions about costs and profitability. The use of structured and unstructured data should be introduced and taught in the management accounting course. In audit practice, software such as IDEA and Tableau are used to form visualizations that are useful when conducting an audit. The authors suggest that this software should be introduced in undergraduate audit courses to promote experiential learning and transference of skills.

Furthermore, utilizing case studies in the audit course can help students better understand how technology can conduct an audit. The authors also included two papers that other papers did not discuss: the accounting information systems (AIS) and tax courses. The AIS course needs to expand on the concepts learned in other accounting courses, but it also needs to provide deeper exposure to data mining and XBRL. Tax courses need to include using research databases used in the profession, like RIA Checkpoint and 
LexisNexis, and explained how the IRS could use data analytics to predict how changes in tax law will affect taxpayer behavior.

Fortunately, some auditing textbooks have begun to include data analysis concepts and techniques, which helps integrate big data into the curriculum. Blix, Edmonds, and Sorensen (2021) analyzed six auditing textbooks and one data analytics textbook to determine how much information and how many problems pertained to the data analytics concepts emphasized by authoritative bodies, like the Pathways Commission, the AACSB, and the American Institution of Certified Public Accountants (AICPA). The three criteria the authors analyzed were: (1) the degree to which textbooks have integrated emerging technologies into the written chapter content; (2) the degree to which auditing textbooks have students perform specific data analysis activities using analytic data software; and (3) the degree to which these problems follow the AICPA's five-step process. Blix, Edmonds, and Sorensen (2021) found that some textbooks included more information about data analytics than others, and some textbooks include more problems focused on the skills identified by the authoritative bodies than others. The authors also found that every textbook utilized at least one data analysis software in its problems. The software included were ACL, Excel, IDEA, and Tableau. This study indicates that data analysis concepts are beginning to be integrated into the course content of textbooks, but integration overall is still developing.

Sarkar, Gray, Boss, and Daly (2021) analyzed how two universities have integrated more data analysis techniques into their curriculum. The first university was a large public institution that modified its graduate AIS course to include more data analysis topics and projects. The course utilized SAP as the accounting information system, ERPsim to create an active learning environment, and Tableau to perform data analysis. Through these applications, the course focused on the generation, extraction, and analysis of accounting data. The researchers discovered that the course received positive feedback from faculty, professionals, and students. The second university Sarkar, Gray, Boss, and Daly (2021) examined was a small private university. Instead of enhancing its undergraduate AIS course, that university decided to make a Master's in Accounting Analytics (MSAA) program. This program involved the coordination of various departments in order to be executed. These departments included the Accounting Department, Computer Science Department, the Information and Process Management (IPM) Department, the Statistics Department, the Finance Department, and the Math Department. The program focused on various software, such as Access, Alteryx, Excel, IDEA, Python, and Tableau, and included a capstone course that utilized the Robotics Process Automation tool UiPath. Since the program involved extensive coordination with other departments, it gave students a strong foundation and understanding of applying analytical software in accounting and other business contexts. Both the large public institution and the small private school's programs received positive feedback from students.

\section{Challenges of Integrating Big Data into the Curriculum}

Integrating technology and big data into accounting education at the undergraduate level is becoming increasingly important. Although many academics have suggested ways to integrate it, challenges need to be to addressed before full integration into the curriculum might be possible. Zhang (2018) explained that the faculty teaching accounting courses might not be aware of the technology currently being used in the profession. As a result, more specialized professors might need to be hired, or more training for current faculty be offered. The author also noted that accounting courses pay too much attention to theoretical 
knowledge rather than preparing students for the tasks they will be doing in their careers. A greater focus on case studies could give students experiential learning opportunities.

Appelbaum, Kogan, and Vasarhelyi (2017) also noted that accounting faculty might not be prepared to teach data analytics. Additionally, the authors mentioned a widespread feeling amongst faculty that accounting students are not ready to learn about data analytics. Since the CPA exam puts little emphasis on understanding technology, students may not have the motivation to learn how to analyze data. The authors also explained that accounting firms are already beginning to hire non-accounting specialist groups to perform complex data analysis because accounting practitioners are also not updated with data analysis technology.

In Sarkar, Gray, Boss, and Daly's (2021) analysis of integrating data analytics into two university accounting programs, similar challenges were faced. Faculty at both universities lacked the training necessary to teach analytical applications and had limited time to learn these tools. For example, software license management and student computers presented challenges. Many students had the Macintosh operating system, and some of the programs utilized in the program did not have Mac versions. Other students' computers lacked the computing power necessary to complete some of the projects.

The main challenge noted is that accounting faculty have low awareness of data analytics and how it applies to accounting. Blix, Edmonds, and Sorensen (2021) indicated that some faculty tended to rely on textbooks to keep them updated but found that the data analysis concepts included in the textbooks were insufficient compared to the criteria requested by authoritative bodies. Fortunately, the American Accounting Association (AAA) provides various resources to educators to teach them how big data is used in accounting and how professors can integrate data analysis concepts into their courses (Janvrin \& Watson, 2017). Each year, AAA hosts an Accounting is Big Data conference where attendees are provided with PowerPoint slides, speakers videos, technology demonstrations, and sample big data syllabi. The AAA also hosts extensive data webinars that provide links to free datasets and tools to educators and additional demonstrations about using data analysis software, like Tableau. The conference and webinars can help faculty learn more about how big data can be used in accounting and infuse data analysis concepts into accounting courses. Additionally, the big four accounting firms and academic accounting journals provide resources to educators in the form of datasets and case studies. By utilizing all these resources, faculty can teach themselves about data analytics and prepare their courses to integrate these concepts.

\section{Summary}

The purpose of this literature review was multifold. First, the speed of adopting big data tools by accountants was discussed. Second, a review of some big data applications for accountants, their implications, and challenges for practice were presented. Lastly, a discussion of implications for curriculum planning for those involved in accounting education programs was put forth.

\section{References}

Appelbaum, D., Kogan, A., \& Vasarhelyi, M. A. (2017). Big data and analytics in the modern audit engagement: Research needs. Auditing: A Journal of Practice \& Theory, 36(4), 1-27. 
Beaulieu, P. R. (2020). Contract-based cost analytics. Journal of Emerging Technologies in Accounting, $17(1), 11-19$.

Blix, L. H., Edmonds, M. A., \& Sorensen, K. B. (2021). How well do audit textbooks currently integrate data analytics. Journal of Accounting Education, 55, 1 - 17.

Borthick, A. F., \& Pennington, R. R. (2017). When data become ubiquitous, what becomes of accounting and assurance? Journal of Information Systems, 31(3), 1 - 4.

Cockcroft, S., \& Russell, M. (2018). Big data opportunities for accounting and finance practice and research. Australian Accounting Review, 28(3), 323 - 333.

Cong, Y., Du, H., \& Vasarhelyi, M. A. (2018). Technology disruption in accounting and auditing. Journal of Emerging Technologies in Accounting, 15(2), 1 - 10.

Dewu, K., \& Barghathi, Y. (2019). The accounting curriculum and the emergence of big data. Accounting and Management Information Systems, 18(3), 417 - 442.

Dzuranin, A. C., Jones, J. R., \& Olvera, R. M. (2018). Infusing data analytics into the accounting curriculum: A framework and insights from faculty. Journal of Accounting Education, 43, 24 39.

Janvrin, D. J., \& Watson, W. M. (2017). "Big data:" A new twist to accounting. Journal of Accounting Education, 38, $3-8$.

Murthy, U., S., \& Geerts, G. L. (2017). An REA Ontology-Based Model for mapping big data to accounting information systems elements. Journal of Information Systems, 31(3), 45 - 61.

Qasim, A., \& Kharbat, F. F. (2020). Blockchain technology, business data analytics, and artificial intelligence: Use in the accounting profession and ideas for inclusion into the accounting curriculum. Journal of Emerging Technologies in Accounting, 17(1), $107-117$.

Rezaee, Z., Dorestani, A., \& Aliabadi, S. (2018). Application of time series analyses in big data: Practical research, and education implications. Journal of Emerging Technologies in Accounting, 15(1), 183 $-197$.

Richins, G., Stapleton, A., Stratopoulos, T. C., \& Wong, C. (2017). Big data analytics: Opportunity or threat for the accounting professions? Journal of Information Systems, 31(3), 63 - 79.

Rose, A. M, Rose, J. M., Sanderson, K. A., \& Thibodeau, J. C. (2017). When should audit firms introduce analyses of big data into the audit process? Journal of Information Systems, 31(3), 81 - 99.

Sarkar, S., Gray, J., Boss, S. R., \& Daly, E. (2021). Developing institutional skills for addressing big data: Experiences in implementation of AACSB standard 5. Journal of Accounting Education, 54, 1 17. 
Schmidt, P. J., Church, K. S., \& Riley, J. (2020). Clinging to Excel as a security blanket: Investigating accountants' resistance to emerging data analytics technology. Journal of Emerging Technologies in Accounting. 17(1), $33-39$.

Sledgianowski, D., Gomaa, M., \& Tan, C. (2017). Toward integration of big data, technology and information systems competencies into the accounting curriculum. Journal of Accounting Education, 38, $81-93$.

Smidt, L., Ahmi, A., Steenkamp, L., van der Nest, D. P., \& Lubbe, D. (2019). A maturity-level assessment for generalized audit software: Internal audit functions in Australia. Austrian Accounting Review, $29(3), 516-531$.

Tapis, G. P., \& Priya, K. (2020). Developing and assessing data analytics courses: A continuous proposal for responding to AACSB standard A5. Journal of Emerging Technologies in Accounting, 17(1), $133-141$.

Zhan, J., Her, Y. W., Hu, T., \& Du, C. (2018). Integrating data analytics into the undergraduate accounting curriculum. Business Education Innovation Journal, 10(2), 169 - 178.

Zhang, Y. (2018). Model innovation and teaching effect evaluation of accounting teaching in higher vocational colleges in the era of big data. Educational Sciences: Theory \& Practice, 18(6), 3620 -3627 . 